\title{
Modeling and Simulation of Hydraulic Gap Control System in a Hot Strip Mill
}

\author{
Prodip BHOWAL and S. K. MUKHERJEE'1)
}

Automation Division, The Tata Iron and Steel Co., Ltd., Jamshedpur, India 831001.

1) Department of Electrical Engineering, Regional Institute of Technology, Jamshedpur, India 831014.

(Received on July 26, 1995; accepted in final form on January 18, 1996)

\begin{abstract}
Hot strips are presently being rolled out with considerable thickness accuracy. This has been made possible due to superordinated control system comprising of adaptive setup model, monitor thickness control, automatic gauge control, tension and looper control, hydraulic gap control etc.

The present work is, however, confined to modeling and simulation studies of hydraulic gap control system in the last stand of the finishing mill of a typical hot strip mill (HSM). The simulation results based on the model show that the system operates effectively to provide high thickness accuracy and good response behavior.
\end{abstract}

KEY WORDS: hydraulic gap control; thickness control; modeling and simulation; hot strip mill.

\section{Introduction}

A typical hot strip mill designed for rolling cast slabs consists of reheat furnace, hydraulic descaler, reversible roughing stand, coil box, crop shear, finishing stands, interstand cooling sprayers, runout table, down coiler and a host of important controls.

The output of the slab caster is charged into the reheat furnace before rolling. The oxides found in the soaked slab are descaled by high pressure water jets. Major thickness reduction of the slab takes place in the roughing stand. The desired rolling thickness is achieved by multipass reversible rolling. A pair of vertical edges are provided to control the width of the semi-rolled slabs. The finishing stand is a continuous mill consisting of five or more number of 4-high stand. The output from the finishing stand is cooled using cooling sprayers at a particular rate to achieve desired metallurgical and mechanical properties. Finally, the rolled strips coming from finishing stand are coiled in the down coiler for further processing.

The various factors which contribute to thickness variation during rolling are temperature, roll eccentricity, rolling force, mill speed, oil film thickness in roll bearings, impact transients, mill stretch, interstand tension, strip modulus, slippage and roll gap.

Over the years, considerable research efforts have been directed in this field. Kondo et al. $^{1 \text { ) }}$ have shown that the AGC thickness control system controlling the strip tension (reel motor current) is better than the AGC system controlling the roll position even with a hydraulic screw down system. The new AGC system proposed included both the roll position and motor current control. Holton ${ }^{2)}$ determined the ratio of actual (measured) and calculated (setup) rolling load at the early stands and then using that ratio to correct the predicted rolling load for the final three stands. To improve the performance further, a thickness meter was installed between finishing stands 4 and 5 and a new feedforward control employed. Yamada ${ }^{3)}$ addressed the problem of unequal distribution among the stands as well as accuracy of the mill setup for stable operation of rolling. In order to solve this problem, an algorithm of optimal correction for each stand in the finishing mill was developed and successfully implemented in New Zealand HSM.

Haraki et $\mathrm{al}^{4)}$ reported the installation of interstand thickness meter coupled with a new feedforward control system in the HSM of Kashima Steel Works, Japan. This improved the thickness accuracy at the strip head end also. Seki et al. ${ }^{5)}$ developed optimal multivariable control system to maintain constant strip tension in the presence of rapid changes in the hot strip finishing mill at Hirohata Works of Nippon Steel Corporation. In short, it can be said that modern thickness control is characterized by the cohesive blend of enhanced $A G C$ and automatic mill setup.

In this paper an attempt has been made to develop a simple, yet effective, model of hydraulic gap or position control system from the transfer function blocks and make simulation studies. ${ }^{6}$

\section{System under Investigation}

The automatic thickness control system of HSM consists of setup calculation (SUC), monitor thickness control (MTC), automatic gauge control (AGC), hydraulic gap control (HGC), tension control (TC), digital 


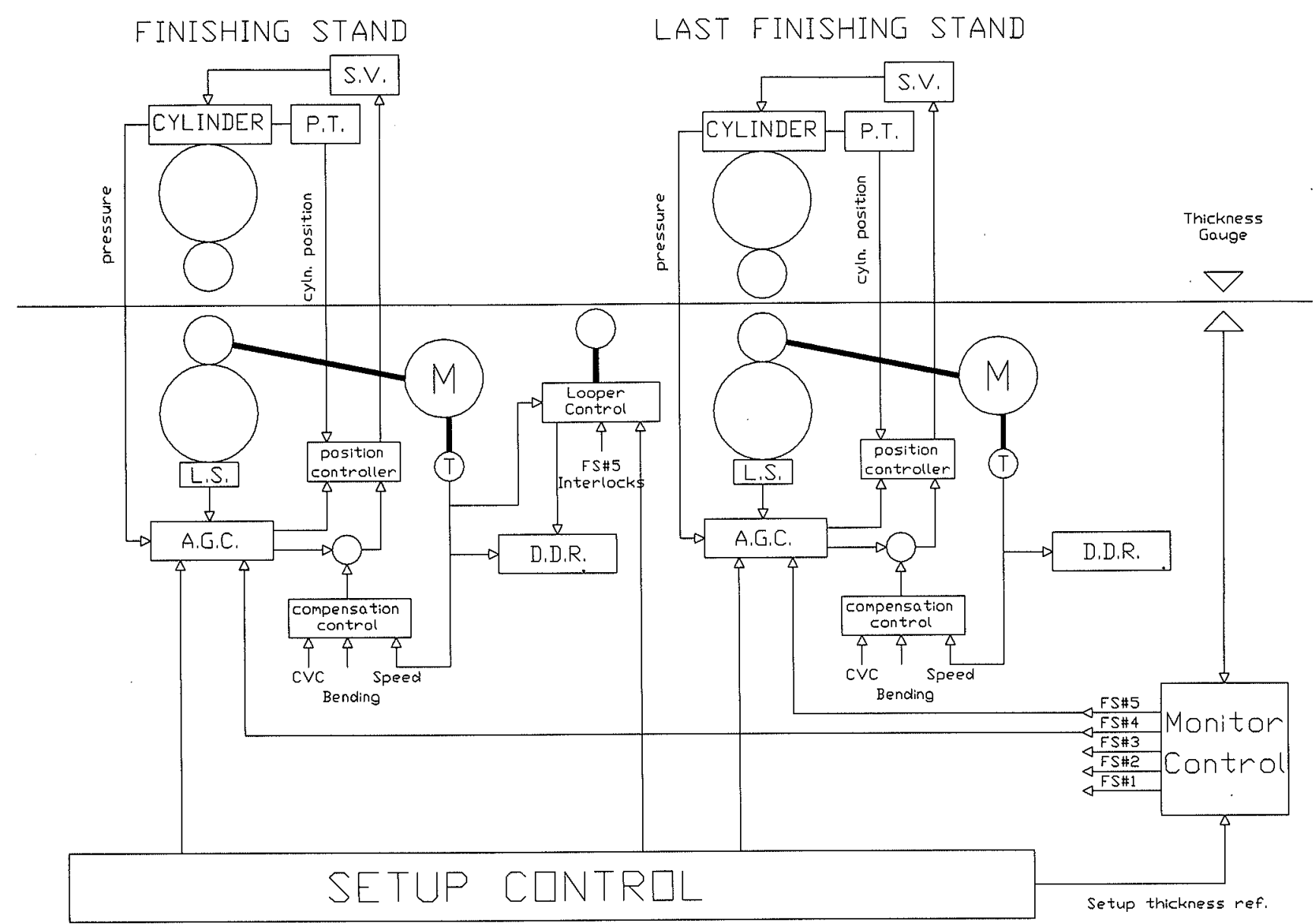

S.V.: Servo Valve

P.T.: Position Transducer

L.S.: Load Cell
A.G.C.: Automatic Gauge Controller

D.D.R.: Digital Drive

C.V.C.: Continuous Variable Crown Compensation

Fig. 1. Block diagram of hydraulic gap control with superordinated thickness control.

drive control (DDC) and compensation controls.

A block schematic of the control system is shown in Fig. 1. The setup calculation is an adaptive model which generates necessary set-points for MTC, AGC and Looper. Based on the requirements of rolling viz., number of coils, steel grade, entry gauge, exit gauge, width, entry temperature, exit temperature, etc., and the limitation of the mill viz., force, power, tension and speed; the mathematical setup determines setup values, such as rolling temperature, deformation resistance, forward slip, reduction of thickness on each stand, drive speed, interstand tensions, roll separating force and roll gap presets.

Based on the setup values and thickness from the $\mathrm{X}$-ray gauge, MTC provides feedback correction to AGCs of all finishing stands. The AGC is the superposed control system, which controls the roll gap using the basic HGC. It also compensates for work roll shifting, roll bending, roll wear, thermal expansion of rolls and bearing eccentricity etc.

Depending upon the setup control, monitor control feedback, roll separating forces and cylinder pressure inputs to $\mathrm{AGC}$ and compensation control, the $\mathrm{AGC}$ generates the setpoint for HGC. The HGC does the job of actually moving the rolls and creating necessary rolling force. The typical HGC has high response servovalves, hydraulic cylinders, high precision measurement of cylinder movements. The direct control of the screwdown cylinder is performed by the HGC with position and force control.

A detail block diagram of HGC is shown in Fig. 2. From this input-output description, field and operating parameters, mill housing stretch and oil compression ratio, a suitable model of HGC was developed and simulated on a personal computer using software package. Valve non-linearity was avoided by assuming the operation to be in the linear region. The limiting values of system parameters and variables were incorporated in the simulation models, however.

\section{HGC Model}

The governing mathematical expressions and parameters used in developing the model are summarized as shown.

\subsection{Servo Valve}

$$
Q=Q_{\text {nom }} \frac{I}{I_{\max }}\left(\frac{\Delta p}{P_{\text {nom }}}\right)^{1 / 2}
$$

where, $Q$ : actual flow

$$
Q_{\text {nom }} \text { : nominal flow }
$$


$P_{\text {nom }}:$ nominal pressure

$\Delta p:$ pressure drop across the valve

$I$ : current supplied to the solenoid by the amplifier

$I_{\max }:$ maximum solenoid current.

\subsection{Pipe Line}

Transmission delay of hydraulic oil in the pipe line is very small and hence neglected.

\subsection{Cylinder}

It converts flow into corresponding pressure and force. The total volume of oil delivered to the piston is the integration of the flow. The actual volume of oil after compression is equal to the actual volume inside the cylinder and is calculated by multiplying piston area and displacement.

The corresponding volume

$$
v=V_{\mathrm{Q}}-V_{\mathrm{g}}
$$

where, $V_{\mathrm{Q}}:$ volume of oil supplied

$V_{\mathrm{g}}$ : actual volume of oil under compression.

A schamatic block diagram of the hydraulic circuit for one of the cylinders is shown in Fig. 3. In practice two cylinders shall be provided for both the ends of the roll. The falling of rolls due to its own weight, when rolling force is not applied, is prevented by providing a constant oil pressure at the rod side of the cylinder.

The amount of line pressure generated equals Line pressure

$$
=\text { compression ratio } \times \text { oil compression factor }(\mathrm{OC})
$$

$$
=\frac{\Delta V}{V_{\mathrm{g}}} \times \mathrm{OC}
$$

Piston side force $\left(F_{\mathrm{p}}\right)=$ line pressure $\times$ piston area ....(4)

Rod side of the cylinder is under constant low pressure and exerts an opposite force $\left(F_{\text {rod }}\right)$ to the piston side force $\left(F_{\mathrm{p}}\right)$.

$$
\text { Resultant rolling force }=\left(F_{\mathrm{p}}-F_{\text {rod }}\right)
$$

where, $F_{\text {rod }}$ : constant force exerted in the rod side of the cylinder by the constant oil pressure

$F_{\mathrm{p}}$ : force exerted in the piston side of the cylinder.

\subsection{Mill}

It converts rolling force into cylinder displacement against roll separating force. The roll separating force is a function of thickness reduction and strip modulus.

Roll separating force

$$
=(\text { strip modulus } \times \text { thickness reduction })
$$

Thickness reduction

$$
=\text { (entry thickness - loaded thickness) }
$$

The resultant of cylinder force and roll separating force causes movement of rolls. The acceleration produced in the rolls is calculated by dividing the resultant force by effective roll mass. The successive integration of acceleration yields piston velocity and displacement under loaded condition. For a $120 \mathrm{~mm}$ stroke cylinder,
Roll displacement $=(120-$ cylinder displacement $)$

The rolling process causes large amount of force and consequently mill housing stretch.

Housing stretch $=($ cylinder force $\times$ stretch modulus $)$

The actual loaded gap is the resultant of cylinder movement and housing stretch.

\subsection{Controller}

It is a PID controller having transfer function

$$
\left(K_{\mathrm{p}}+K_{\mathrm{i}} / s+K_{\mathrm{d}} \cdot s\right)
$$

where, $K_{\mathrm{p}}$ : proportional coefficient of the controller

$K_{\mathrm{i}}$ : integral coefficient of the controller

$K_{\mathrm{d}}$ : derivative coefficient of the controller.

The coefficients are adjusted to control the dynamics of the process and achieve thickness accuracy.

System parameters, rolling parameters and other data given in the appendix.

\section{Simulation Results}

Complete simulation models of various sub-systems of $\mathrm{HGC}$ were developed taking into consideration the limiting values of variables under normal operating conditions of the mill. Subsequently, the simulation plots of rolled thickness and set-point, rolling and roll separating force, line pressure were obtained for entry thickness variations with sinusoidal and step disturbances. The controller parameters, sampling time, system parameters and roll mass were kept constant.

Figure 4 shows such plots with good transient behavior and thickness accuracy. Figure $\mathbf{5}$ is a repeat of plots shown in Fig. 4, but with step disturbance in place of sinusoidal disturbance. The plots again show good response behavior.

The comparison of practical thickness obtained in the HSM with that of simulation run was quite encouraging. The thickness deviation was of the order of 100-200 $\mu \mathrm{m}$ sinusoidal with a setup bias. Without the setup bias, shown in Fig. 6, the accuracy was rather poor. It was also seen that with input step disturbance, the output thickness deviation reduces to zero quickly. Figures 7 to $\mathbf{1 0}$ show simulation plots of rolled thickness with variation in proportional controller settings $K_{\mathrm{p}}$ from 400 to 10000 and roll weight variations from 50 to $150 \mathrm{t}$. In each of these plots the best choice of sampling time obtained was $1 \mathrm{~ms}$. For higher values, the simulation gave poor control of thickness. The lower value of $K_{\mathrm{p}}$ introduced sluggishness in the system whereas higher $K_{\mathrm{p}}$ made the system behavior oscillatory. Higher roll mass exhibited poor stabilization and response behavior.

\section{Conclusion}

The paper developed a linearized simple workable model of $\mathrm{HGC}$ in a hot strip mill and carried out simulation studies. Such studies are useful from the point of dynamic behavior, stability, safe operating limits of 


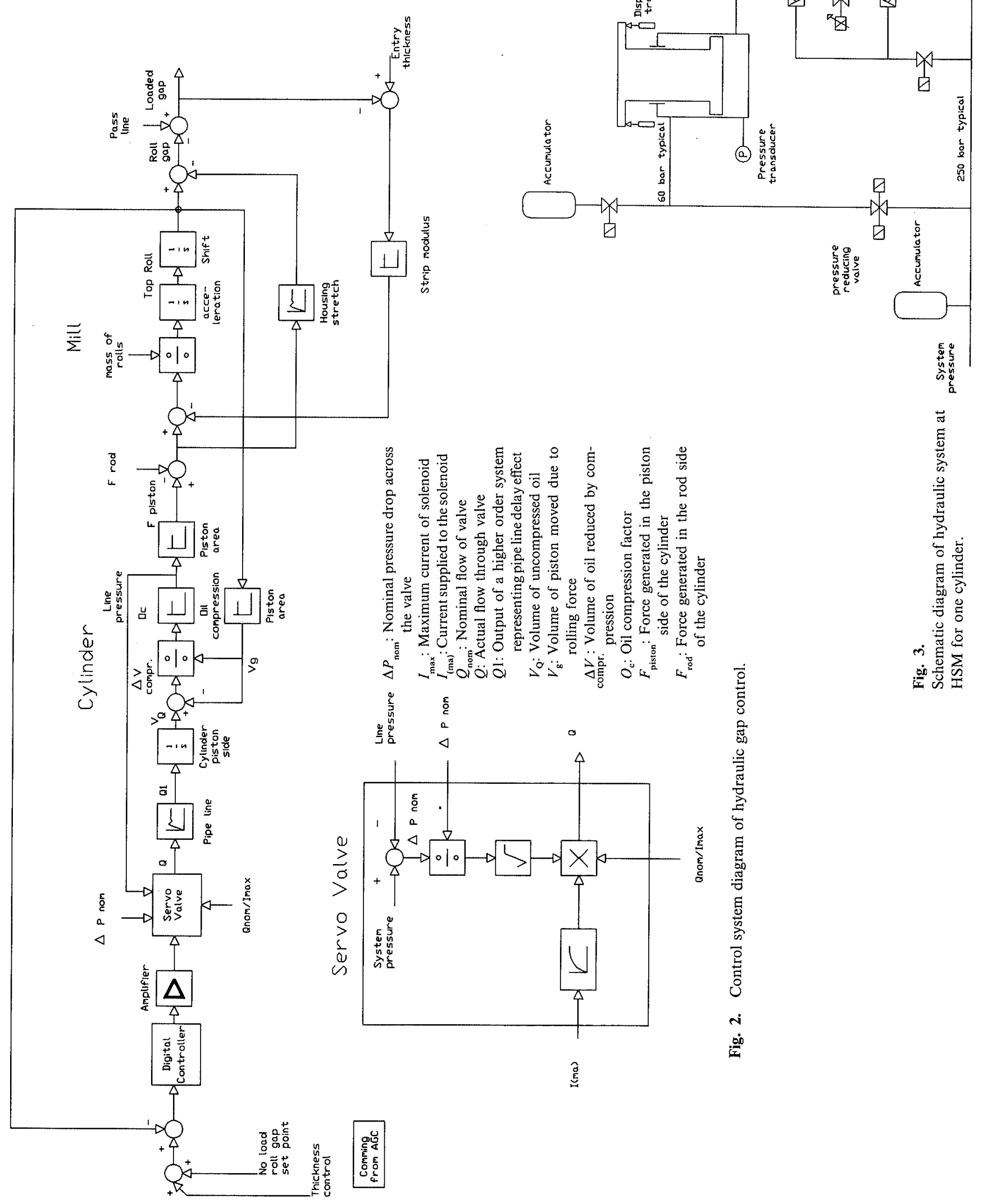


ISIJ International, Vol. 36 (1996), No. 5
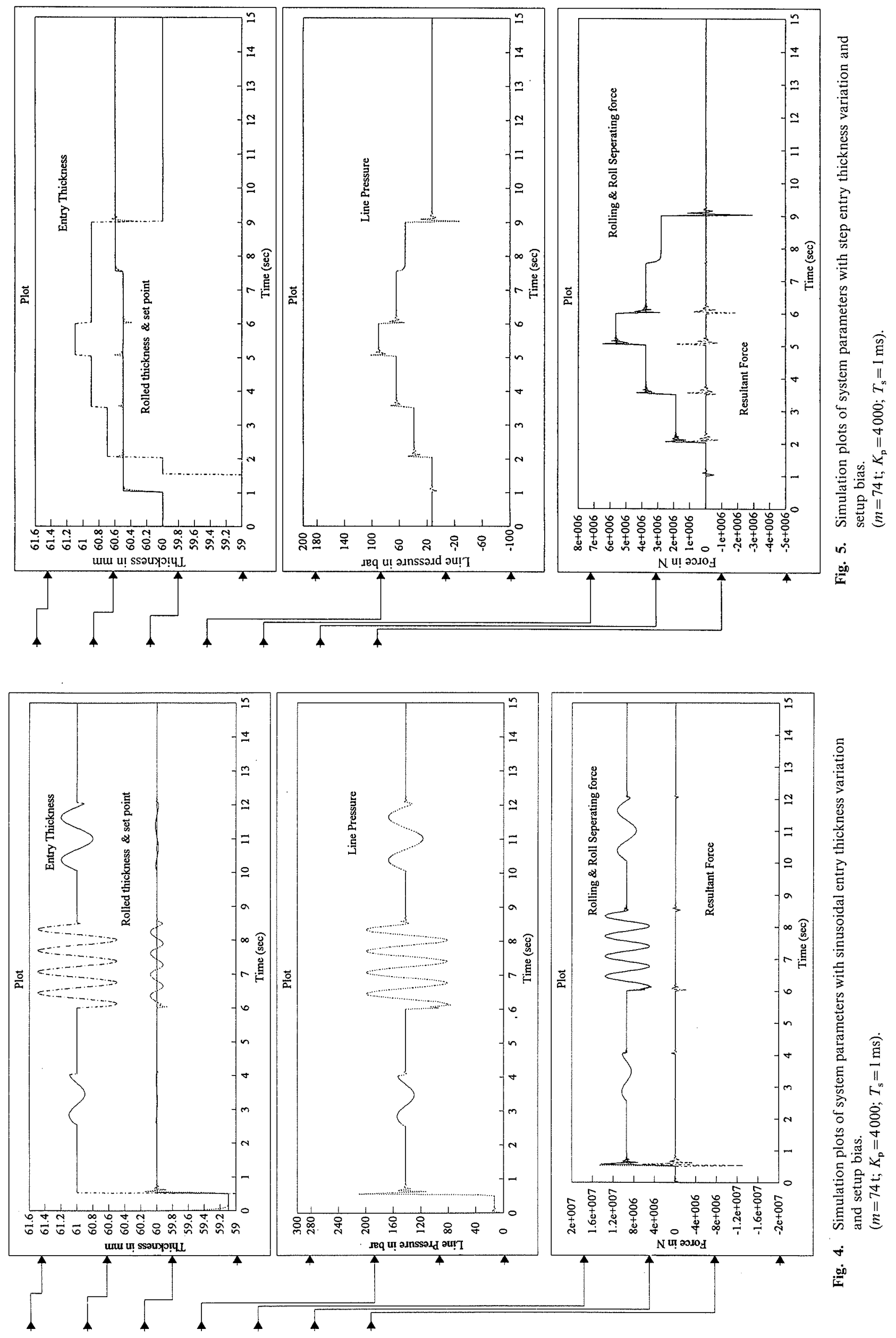
ISIJ International, Vol. 36 (1996), No. 5
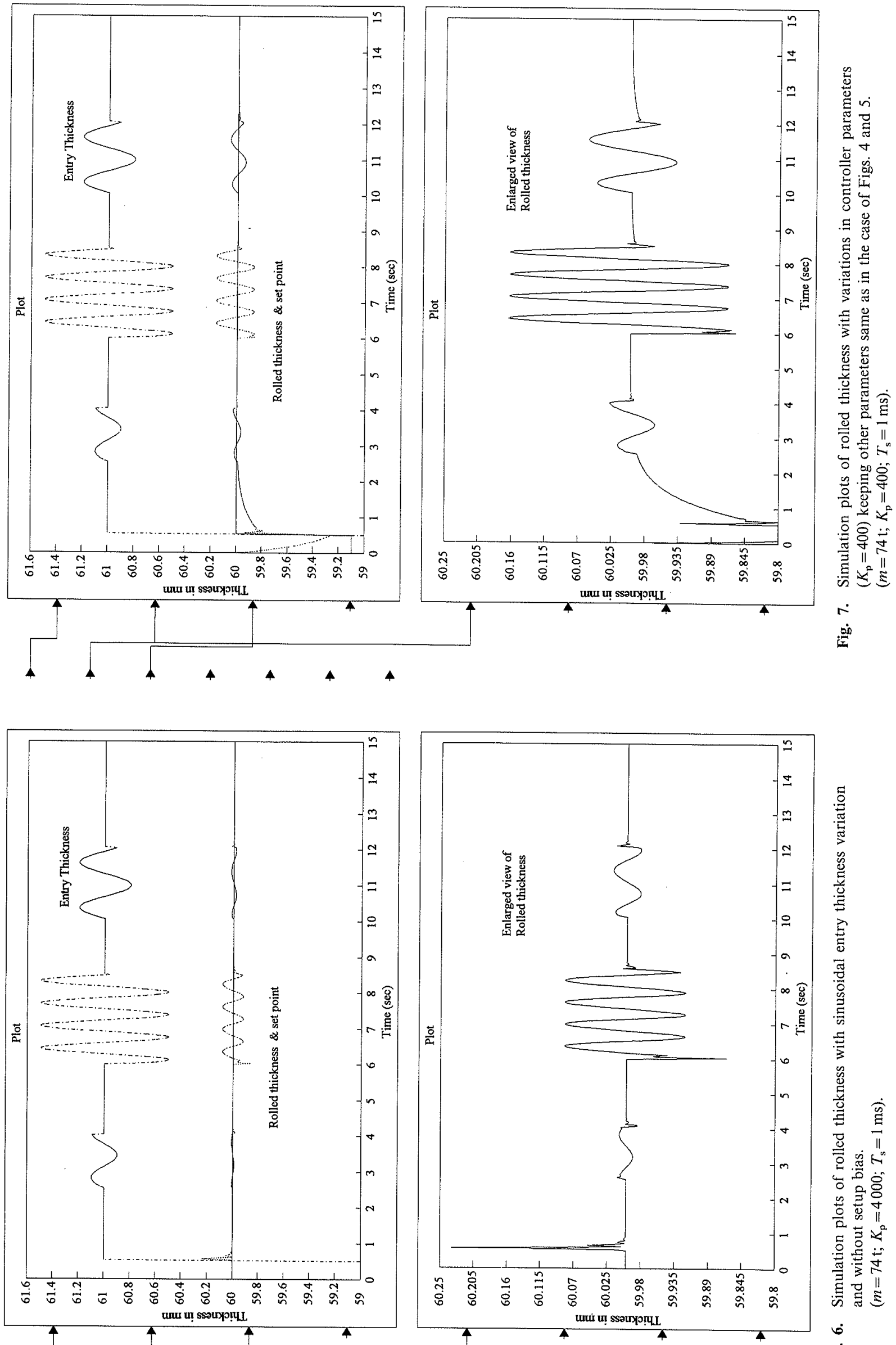

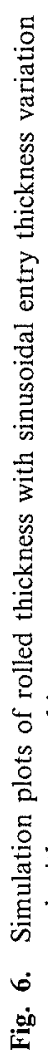


ISIJ International, Vol. 36 (1996), No. 5
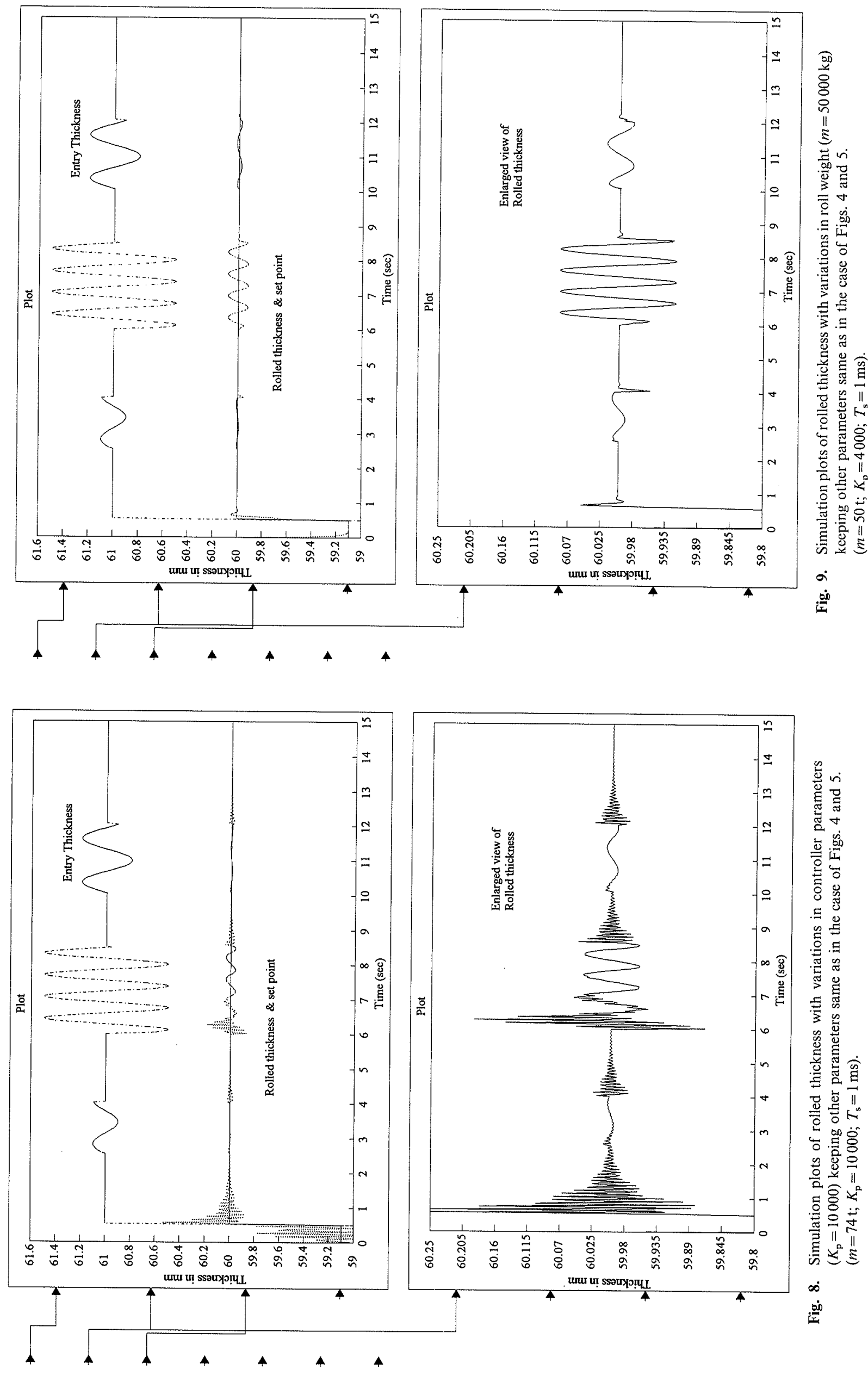

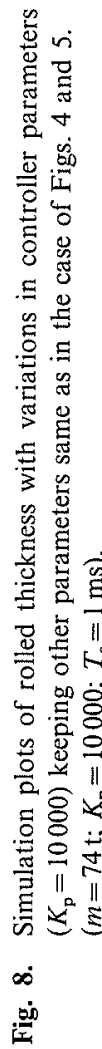



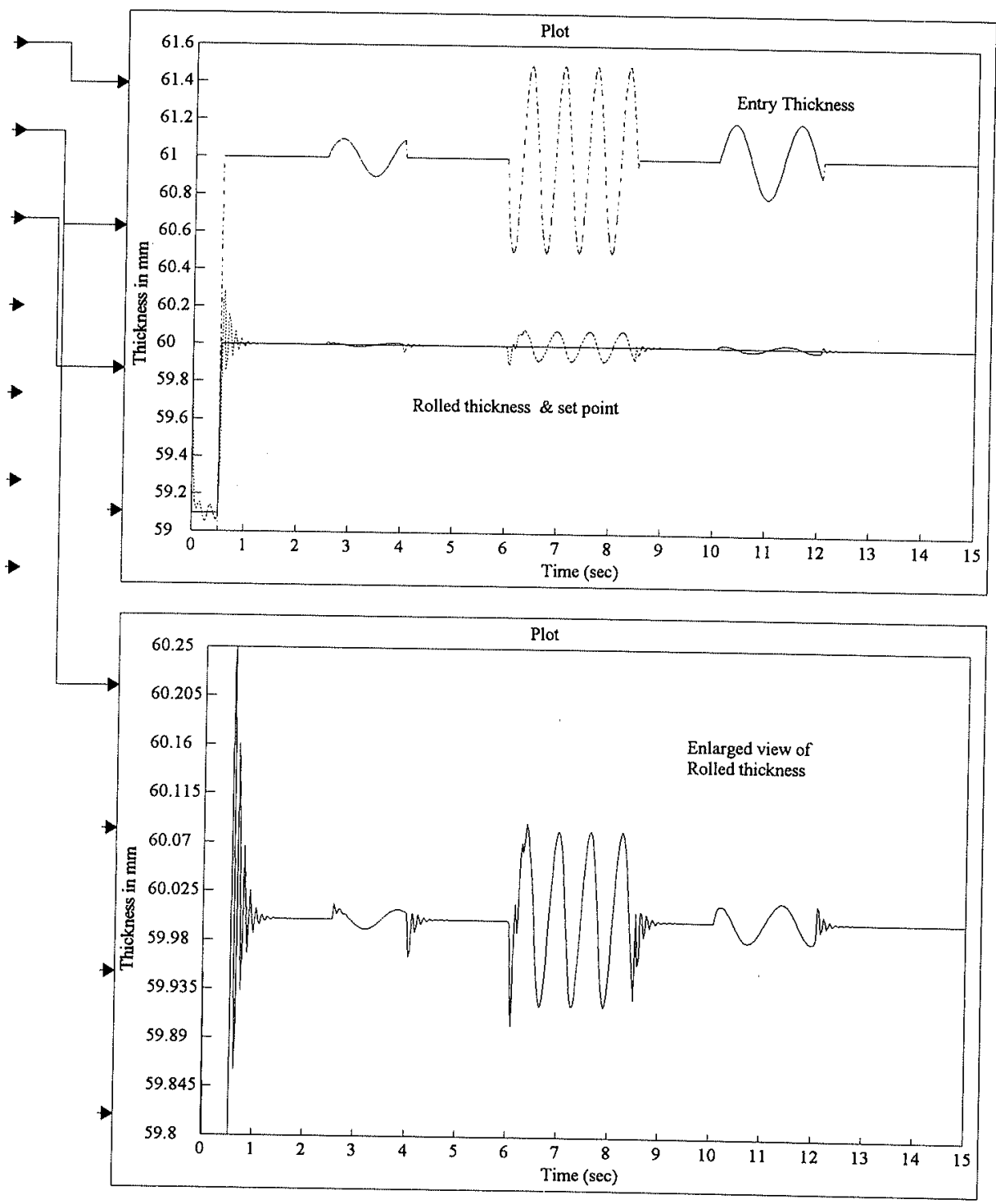

Fig. 10. Simulation plots of rolled thickness with variations in roll weight ( $m=150000 \mathrm{~kg}$ ) keeping other parameters same as in the case of Figs. 4 and 5 . $\left(m=150 \mathrm{t} ; K_{\mathrm{p}}=4000 ; T_{\mathrm{s}}=1 \mathrm{~ms}\right)$.

variables, effects of disturbance and parameter changes on rolled thickness, controller design etc.

The thickness deviation of rolled strip and its response behavior under entry thickness variation, system and controller parameter variations were very encouraging. Thickness accuracy within 10-20 $\mu \mathrm{m}$ was achieved for entry thickness variation as high as $100-200 \mu \mathrm{m}$. The system exhibited highly stable and fast response thickness control under step disturbance.

Further investigation showed that a proportional controller was good enough to the system under study. In the analysis, the effects of dead-time and non-linearity were not considered for obvious reasons. However, the same may be incorporated in the simulation model for rigorous analysis.

\section{REFERENCES}

1) K. Kondo, Y. Misaka, M. Okamato, Y. Matsumori and T. Miyagi: Trans. Iron Steel Inst. Jpn., 28 (1988), 507.

2) L. J. Holton: Iron Steel Eng., 67 (1990), 42.

3) F. Yamada, K. Sekiguchi, M. Tsugeno, Y. Anbe, Y. Andoh, C.
Forse, M. Guernier and T. Coleman: IEEE Trans. Ind. Appl., 27 (1991), 131

4) H. Hiraki, R. Takahashi and K. Kimura: Iron Steel Engr., 69 (1992), 54.

5) Y. Seki, K. Sekiguchi, Y. Anbe, K. fukushima, Y. Tsuji and S. Ueno: IEE Trans. Ind. Appl., 27 (1991), 124

6) P. Bhowal: M. Sc. Engg. dissertation, Dept. of Electrical Engineering, Regional Institute of Technology, Jamshedpur, India, (1995)

\section{Appendix. System Parameter Selection}

The major system parameters are obtained from the field information. The data of the main equipment were collected from the respective plants. Considering small variation of the operating point during simulation, all nonlinear parameters were linearised by simple averaging. The detail of all parameters are given in this section.

Mass of Rolls

Since it is a two-high mill, each stand consists of two working rolls and two back-up rolls. The bottom set of 
rolls are stationary during rolling. The top side of rolls are attached with hydraulic cylinder and move up and down along with the movements of cylinder. The rolls are placed with suitable chock and bearing. The total weight of rolls and chocks are supported by a hydraulic cylinder. Therefore, total weight considered as roll weight by the model is as follows:

Total weight $=$ weight of work roll + weight of work roll chock + weight of backup roll + weight of backup roll chock

$$
\begin{aligned}
& =7+7+28+32(\mathrm{t}) \\
& =74(\mathrm{t})
\end{aligned}
$$

Hydraulic System Parameters
a) Cylinder:
i) rod side area
$1639 \mathrm{~cm}^{2}$
ii) piston side area
$7310 \mathrm{~cm}^{2}$
iii) stroke length
$12 \mathrm{~cm}$

b) System pressure: $250 \mathrm{bar}$

c) Rod side pressure: $60 \mathrm{bar}$

Note: The above mentioned pressures are maintained constant by providing necessary accumulators.

d) Servo valve:
i) $Q_{\text {nom }}$
ii) $p_{\text {nom }}$
$40 \mathrm{l} / \mathrm{min}$
iii) $I_{\max }$
70 bar
iv) $p_{\text {sys }}$
$20 \mathrm{~mA}$
250 bar

e) Oil compression factor: Data available from standard hydraulic hand book are

$\begin{array}{rcr} & \% \text { compression } & \text { pressure } \\ \text { i) } & 0.5 \% & 70 \mathrm{bar} \\ \text { ii) } & 1.0 \% & 140 \mathrm{bar} \\ \text { iii) } & 1.1 \% & 210 \mathrm{bar}\end{array}$

The above data shows a nonlinear relation. Considering the operating point between 140 and $210 \mathrm{bar}$, the coefficient can be linearised by averaging.

Therefore, averaging the area at 140 to $210 \mathrm{bar}$, the compression factor calculated is $(18000$ bar)/(compression ratio) where the compression ratio is defined as $\left(\Delta V / V_{\mathrm{g}}\right)$. See Eq. (3).

\section{Mill Housing Stretch}

This coefficient, multiplied by the applied force on mill housing gives the amount of expansion or contruction. A table of measured value is given below:

$\begin{array}{cc}\text { force } & \text { stretch } \\ 1.25 \mathrm{MN} & -1.736 \mu \mathrm{m} \\ 5.00 \mathrm{MN} & -0.932 \mu \mathrm{m} \\ 10.00 \mathrm{MN} & 0 \\ 25.00 \mathrm{MN} & +2.532 \mu \mathrm{m}\end{array}$

Note: Here negative sign indicates compression due to dead weight of rolls and positive sign indicates elongation due to roll separating force exerted during rolling.

Since the roll and associated components are continuously hanging on the housing, the mill stretch is calculated from the above data, considering $10 \mathrm{MN}$ as balancing force for roll weight and other component weight.

Therefore

$$
\text { Stretch }=k(F-10) \mu \mathrm{m}
$$

where $k$ is modulus of elasticity.

The values of $k$ obtained from the experimental values are:

$$
\begin{aligned}
& k 1=-1.736 /(1.25-10)=0.1986 \mu \mathrm{m} / \mathrm{MN} \\
& k 2=-0.932 /(5-10)=0.1864 \mu \mathrm{m} / \mathrm{MN} \\
& k 3=2.532 /(25-10)=0.1688 \mu \mathrm{m} / \mathrm{MN}
\end{aligned}
$$

The above results show that the mill stretch is a nonlinear property. In the present model an average value of $k$ is taken as $0.1846 \mu \mathrm{m} / \mathrm{MN}$.

\section{Strip Modulus}

Strip modulus of any semi-rolled slab depends mainly on a) grade of steel b) entry temperature c) cooling rate of rolls and strip during rolling. For the purpose of this model, data from a rolling schedule were collected for calculating the strip modulus. The rolling parameters of the last stand are given below:
i) Thickness
entry
$3.36 \mathrm{~mm}$
ii) Width
exit
$2.83 \mathrm{~mm}$
iii) Temperature (exit)
iv) Speed
$1230 \mathrm{~mm}$ $900^{\circ} \mathrm{C}$
v) Roll separating force
$7.8 \mathrm{~m} / \mathrm{s}$
vi) Grade
$10000 \mathrm{kN}$
mild steel

Therefore strip modulus in the above condition is

$$
\begin{aligned}
\text { Strip modulus } & =10000 /(3.36-2.83) \mathrm{kN} / \mathrm{mm} \\
& =18868 \mathrm{KN} / \mathrm{mm}
\end{aligned}
$$

System Force Calculation

Maximum force that can be generated per cylinder is

$$
\begin{aligned}
& =7310 \times 250 \times 10 \mathrm{~N} \\
& =18275 \mathrm{kN}
\end{aligned}
$$

with the following considerations:

i) strip modulus is $18868 \mathrm{kN} / \mathrm{mm}$.

ii) total deformation force is shared by both the cylinders equally.

For $1 \mathrm{~mm}$ reduction force required per cylinder is

$$
=9434 \mathrm{kN} / \mathrm{mm}
$$

Therefore, maximum allowable reduction with full operating force

$$
\begin{aligned}
& =18275 \mathrm{kN} / 9434 \mathrm{kN} \cdot \mathrm{mm}^{-1} \\
& =1.93714 \mathrm{~mm}
\end{aligned}
$$

In the above sample, reduction was $0.53 \mathrm{~mm}$. In the present system, the maximum reduction with a given strip modulus of $9434 \mathrm{kN} / \mathrm{mm}$ per cylinder is restricted to $1 \mathrm{~mm}$ only.

\section{Important Parameters Used in Simulation}

1. Sample time: $1 \mathrm{~ms}$

2. PID controller: $K_{\mathrm{p}}=4000, K_{\mathrm{i}}=0, K_{\mathrm{d}}=0$

3. Strip modulus: $9.434 \times 10^{6} \mathrm{~N} / \mathrm{mm}$ per cylinder

4. Rod side force: $9.834 \times 10^{5} \mathrm{~N}$

5. Roll weight: $74 \mathrm{t}$ Viscous friction constant $(\mathrm{f} / \mathrm{m}): 81.081$ 
ISIJ International, Vol. 36 (1996), No. 5

Spring constant $(\mathrm{K} / \mathrm{m}): \quad 8.443 \times 10^{-3}$

6. Oil compression : $18000 \mathrm{~N} /$ compression ratio factor

7. Servo valve $Q_{\text {nom }} 40 \mathrm{l} / \mathrm{min}$ $I_{\max } 20 \mathrm{~mA}$

$P$ nom 70 bar

\section{Parameter Variation}

Proportional gain $\left(K_{\mathrm{p}}\right): \quad 400-10000$

Roll weight $\quad: 50-150 \mathrm{t}$

Sample time $\quad: 1 \mathrm{~ms}-10 \mathrm{~ms}$ 